\title{
Bencze syndrome
}

INSERM

\section{Source}

INSERM. (1999). Orphanet: an online rare disease and orphan drug data base. Bencze syndrome. ORPHA:1241

Bencze syndrome or hemifacial hyperplasia with strabismus is a malformation syndrome involving the abnormal growth of the facial skeleton as well as its soft tissue structure and organs, and is characterized by mild facial asymmetry with unaffected neurocranium and eyeballs, as well as by esotropia, amblyopia and/or convergent strabismus, and occasionally submucous cleft palate. Transmission is autosomal dominant. There have been no further descriptions in the literature since 1979. 